\title{
Burkholderia cepacia genomovar VI, a new member of the Burkholderia cepacia complex isolated from cystic fibrosis patients
}

\author{
Tom Coenye, ${ }^{1}$ John J. LiPuma, ${ }^{2}$ Deborah Henry, ${ }^{3}$ Bart Hoste, ${ }^{4}$ \\ Katrien Vandemeulebroecke, ${ }^{4}$ Monique Gillis, ${ }^{1}$ David P. Speert ${ }^{3}$ \\ and Peter Vandamme ${ }^{1}$
}

1,4 Laboratorium voor
Microbiologie ${ }^{1}$ and
BCCM/LMG Bacteria
Collection ${ }^{4}$, Universiteit
Gent, K.-L.
Ledeganckstraat 35,
Ghent, Belgium
2 Department of Pediatrics
and Communicable
Diseases, University of
Michigan Medical School,
Ann Arbor, MI, USA
3 Department of Pediatrics,
Division of Infectious and
Immunological Diseases,
University of British
Columbia, Vancouver,
British Columbia, Canada
Author for correspondence: Tom Coenye. Tel: +329264 51 14. Fax: +3292645092. e-mail: tom.coenye@rug.ac.be
Keywords: Burkholderia cepacia complex, cystic fibrosis, taxonomy, genomovar

A polyphasic taxonomic study was performed on 23 strains isolated from cystic fibrosis (CF) patients in the USA. These strains were tentatively identified as Burkholderia cepacia, Burkholderia vietnamiensis and Burkholderia or Ralstonia sp. using biochemical tests and 16S rDNA-based PCR assays. Visual comparison of protein profiles indicated that they belonged to a single new group ('group 13'). The polyphasic taxonomic data showed that 18 of these strains represent a new member of the $B$. cepacia complex, referred to in this report as $B$. cepacia genomovar $V I$, whereas the other five strains belonged to Burkholderia multivorans. By means of biochemical tests, B. cepacia genomovar VI strains can be separated from B. cepacia genomovars I and III, Burkholderia stabilis, $B$. vietnamiensis and Burkholderia gladioli, but not from B. multivorans. Separation of $B$. cepacia genomovar VI and B. multivorans is possible using AFLP (amplified fragment length polymorphism) fingerprinting and DNA-DNA hybridizations. Retrospective analysis of epidemiological and genotypic data suggests that strains of $B$. cepacia genomovar VI have been involved in chronic colonization of CF patients and have been spread from person to person.

\section{INTRODUCTION}

In previous studies (Vandamme et al., 1997, 2000) it has been shown that presumed Burkholderia cepacia strains isolated from cystic fibrosis $(\mathrm{CF})$ patients and the environment belong to at least five different genomic species, referred to collectively as the $B$. cepacia complex. One of these genomic species was identified as the previously described Burkholderia vietnamiensis (Gillis et al., 1995) and the names Burkholderia multivorans and Burkholderia stabilis have been proposed for strains classified as B. cepacia genomovars II and IV, respectively (Vandamme et al.,

Abbreviations: AFLP, amplified fragment length polymorphism; CF, cystic fibrosis.

The GenBank accession numbers for the 16S rRNA gene sequences of LMG 18941, LMG 13010 ${ }^{\top}$ and LMG 16656 are AF175314, AF148555 and AF148556, respectively.
1997, 2000). Only B. cepacia genomovar III now awaits a formal binomial species name assignment, pending the availability of differential phenotypic tests (Vandamme et al., 2000). In the absence of epidemic spread, B. cepacia only infects a small proportion of $\mathrm{CF}$ patients but it has a major impact on both morbidity and mortality of infected patients; the medical and psychosocial implications of B. cepacia colonization and segregation of colonized and noncolonized patients as a means of infection control are enormous (LiPuma, 1998a). Accurate identification of $B$. cepacia is crucial in patient management and infection control practices, but may be problematic and misidentification is relatively common (LiPuma, 1998b).

The present study was initiated by the deposit of several strains isolated from sputa of CF patients in the USA in the B. cepacia Research Laboratory and Repository (University of Michigan, MI, USA). Using 
biochemical characterization and 16S rDNA-based PCR assays, these strains were tentatively identified as B. cepacia, B. vietnamiensis and Burkholderia or Ralstonia sp. However, subsequent visual comparison of their protein profiles revealed that these were different and they were tentatively classified as 'group 13'. This report describes the polyphasic taxonomic study which was used for the further characterization of these isolates. The genotypic and phenotypic characteristics allowed the classification of 18 of these strains as a new member of the $B$. cepacia complex which is referred to as B. cepacia genomovar VI.

\section{METHODS}

Bacterial strains and growth conditions. B. cepacia genomovar VI, Burkholderia pseudomallei, B. stabilis and $B$. multivorans strains used in this study are listed in Table 1. Reference strains of other Burkholderia species and genomovars have been described in detail previously (Vandamme et al., 1997). All strains were grown aerobically on Trypticase Soy Agar (BBL) and incubated at $28{ }^{\circ} \mathrm{C}$ unless otherwise indicated.

SDS-PAGE of whole-cell proteins. Strains were grown on nutrient agar (Oxoid CM3) supplemented with $0.04 \%$ (w/v) $\mathrm{KH}_{2} \mathrm{PO}_{4}$ and $0.24 \%(\mathrm{w} / \mathrm{v}) \mathrm{Na}_{2} \mathrm{HPO}_{4} .12 \mathrm{H}_{2} \mathrm{O}(\mathrm{pH} 6 \cdot 8)$ and incubated for $48 \mathrm{~h}$ at $28{ }^{\circ} \mathrm{C}$. Preparation of whole-cell proteins and SDS-PAGE were performed as described previously (Pot et al., 1994). Densitometric analysis, normalization and interpolation of the protein profiles and numerical analysis using the Pearson product-moment correlation coefficient were performed using the GELCOMPAR 4.2 software package (Applied Maths).

DNA preparation. DNA was prepared as described by Pitcher et al. (1989).

Amplified fragment length polymorphism (AFLP) fingerprinting. The preparation of template DNA (using restriction enzymes ApaI and TaqI), amplification [using primers A00 and T00 in the preselective PCR and primers B07 (labelled with the fluorescent dye 6-FAM) and T11 in the selective PCR], separation of the fragments using an ABI Prism 377 automated DNA sequencer and numerical analysis were performed as described previously (Coenye et al., 1999b).

16S rDNA sequencing. The nearly complete sequence (corresponding to positions 8 to 1541 in the Escherichia coli numbering system) of the 16S rRNA gene of strains LMG $13010^{\mathrm{T}}$, LMG 16656 and LMG 18941 was amplified by PCR using conserved primers [5'-AGAGTTTGATCCTGGCTCAG-3' (5'-CTGGCTCAGGAC/TGAACGCTG-3' for LMG 18941) and 5'-AAGGAGGTGATCCAGCCGCA3']. The PCR product was purified using a QIAquick PCR Purification kit (Qiagen) according to the manufacturer's instructions. Sequence analysis was performed using an Applied Biosystems 377 DNA sequencer and the protocols of the manufacturer (Perkin Elmer) using the ABI Prism Dye Terminator Cycle Sequencing Ready Reaction kit. The sequencing primers are those given by Coenye et al. (1999a). Sequence assembly was performed by using the program AUTOASSEMBLER (Perkin Elmer). A phylogenetic tree was constructed with the GENECOMPAR 2.1 software package (Applied Maths), based on the neighbour-joining method
(Saitou \& Nei, 1987). Approximately 1460 bases were used and all unknown bases were excluded for the calculations.

Determination of the DNA base composition. DNA was enzymically degraded into nucleosides as described by Mesbah et al. (1989). The obtained nucleoside mixture was then separated by HPLC using a Waters SymmetryShield C8 column thermostatted at $37^{\circ} \mathrm{C}$. The solvent was $0.02 \mathrm{M}$ $\mathrm{NH}_{4} \mathrm{H}_{2} \mathrm{PO}_{4}$ (pH 4.0) with $1.5 \%$ acetonitrile. Non-methylated lambda phage DNA (Sigma) was used as the calibration reference.

DNA-DNA hybridizations. DNA-DNA hybridizations were performed with photobiotin-labelled probes in microplate wells as described by Ezaki et al. (1989) using a HTS7000 Bio Assay Reader (Perkin Elmer) for the fluorescence measurements. The hybridization temperature was $50{ }^{\circ} \mathrm{C}$.

rRNA-based PCR assay. Assays for the identification of members of the B. cepacia complex based on the rRNA operon are described in detail in a separate study (LiPuma et al., 1999). The following primers were used: RHG-F and RHG-R (specific for all of the Burkholderia and Ralstonia species); PC-SSF and PC-SSR (specific for B. cepacia genomovars I and III, and B. stabilis); BC-GII and BC-R (specific for B. multivorans); and BC-V and BC-R (specific for B. multivorans and B. vietnamiensis).

Fatty acid methyl ester analysis. After an incubation period of $24 \mathrm{~h}$ at $35^{\circ} \mathrm{C}$, a loopful of well-grown cells was harvested and fatty acid methyl esters were prepared, separated and identified using the Microbial Identification System (Microbial ID) as described previously (Vandamme et al., 1992).

Phenotypic characterization. Tests were performed as previously described (Henry et al., 1997). Briefly, pure cultures were stored at $-70{ }^{\circ} \mathrm{C}$ in Mueller-Hinton broth (Difco) with $8 \%$ DMSO. Frozen isolates were subcultured to Columbia agar containing 5\% sheep blood (PML Microbiologicals) before testing. The primary identification system used was the API Rapid NE system (bioMérieux Vitek) with glucose, maltose, lactose, xylose, sucrose and adonitol oxidation-fermentation sugars (Hugh \& Leifson, 1953), and an adaptation of Moeller lysine and ornithine decarboxylases (Difco). In brief, the $2 \mathrm{ml}$ test volume was overlaid with $0.5 \mathrm{ml}$ light mineral oil and a heavy, visible inoculum was used. A tube without amino acid was included as a negative control. Oxidation-fermentation sugars were incubated for up to $7 \mathrm{~d}$ and other tests for $2 \mathrm{~d}$. All incubations were done at $35^{\circ} \mathrm{C}$ except where otherwise mentioned. Growth on Trypticase Soy Agar (Becton Dickinson) at 35 and $42{ }^{\circ} \mathrm{C}$ was observed for appearance and pigment. Phytopathogenicity was tested as described by Gonzalez \& Vidaver (1979). In brief, strains were grown for $24 \mathrm{~h}$ at $28^{\circ} \mathrm{C}$. Bacterial suspensions of $10^{9}$ c.f.u. $\mathrm{ml}^{-1}$ were made in sterile distilled water and $100 \mu \mathrm{l}$ suspension was inoculated on $3-5 \mathrm{~mm}$ thick onion slices. The inoculated onion slices were incubated for $48 \mathrm{~h}$ at $28^{\circ} \mathrm{C}$. B. cepacia genomovar I strain LMG $1222^{\mathrm{T}}$ was used as a positive control. Sterile distilled water was used as a negative control. Growth on agar selective for B. cepacia (DM253; Mast Diagnostics) containing ticarcillin $\left(100 \mu \mathrm{g} \mathrm{ml}^{-1}\right)$ and polymyxin $\mathrm{B}\left(300 \mathrm{U} \mathrm{ml}^{-1}\right)$ was tested by incubating the strains at $37^{\circ} \mathrm{C}$ for $48 \mathrm{~h}$. Ability to grow on BCSA agar (Henry et al., 1997) containing gentamicin $\left(10 \mu \mathrm{g} \mathrm{ml}^{-1}\right)$, polymyxin $\left(600 \mathrm{U} \mathrm{ml}^{-1}\right)$ and vancomycin $\left(2.5 \mu \mathrm{g} \mathrm{ml}^{-1}\right)$ was tested by incubation at $35^{\circ} \mathrm{C}$ under aerobic conditions. 
Table 1 List of strains studied

Abbreviations: CCUG, Culture Collection, University of Göteborg, Department of Clinical Bacteriology, Göteborg, Sweden; LMG, BCCM/LMG Bacteria Collection, Laboratorium voor Microbiologie Gent, Universiteit Gent; ${ }^{\mathrm{T}}$, type strain.

\begin{tabular}{|c|c|c|}
\hline Species and strain designation & Original strain designation & Source \\
\hline \multicolumn{3}{|c|}{ Burkholderia cepacia genomovar VI } \\
\hline LMG 18941 & HI2112 & CF patient (USA) \\
\hline $\mathrm{R}-711$ & HI2110 & CF patient (USA) \\
\hline $\mathrm{R}-726$ & PC543 & CF patient (USA) \\
\hline $\mathrm{R}-733$ & CEP021 & CF patient (USA) \\
\hline LMG 18946 & AU0018 & CF patient (USA) \\
\hline R-2879 & AU0090 & CF patient (USA) \\
\hline LMG 18944 & PC688 & CF patient (USA) \\
\hline R-3074 & PC560 & CF patient (USA) \\
\hline $\mathrm{R}-3200$ & AU0158 & CF patient (USA) \\
\hline LMG 18942 & PC534 & CF patient (USA) \\
\hline R-4055 & AU0266 & CF patient (USA) \\
\hline $\mathrm{R}-4225$ & PC520 & CF patient (USA) \\
\hline $\mathrm{R}-4232$ & AU0169 & CF patient (USA) \\
\hline LMG 18943 & AU0645 & CF patient (USA) \\
\hline R-6140 & AU0746 & CF patient (USA) \\
\hline R-6342 & AU0869 & CF patient (USA) \\
\hline R-6918 & AU0938 & CF patient (USA) \\
\hline R-7394 & AU0981 & CF patient (USA) \\
\hline \multicolumn{3}{|l|}{ Burkholderia stabilis } \\
\hline LMG 13017 & $88 / 190$ & Blood culture (Belgium, 1988) \\
\hline LMG 14086 & $315 / 70$ & Respirator (UK, 1970) \\
\hline LMG 14294 & E3P & CF patient (Belgium, 1993) \\
\hline LMG 7000 & CCUG 13348 & Blood (Sweden, 1983) \\
\hline LMG 14295 & E4P & CF patient (Belgium, 1993) \\
\hline \multicolumn{3}{|l|}{ Burkholderia multivorans } \\
\hline LMG $13010^{\mathrm{T}}$ & CEPA002 $2^{\mathrm{T}}$ & CF patient (Belgium, 1992) \\
\hline LMG 18824 & FC147 & $\begin{array}{l}\text { Chronic granulomatous disease } \\
\text { patient (Canada) }\end{array}$ \\
\hline LMG 18822 & C5393 & CF patient (Canada) \\
\hline LMG 18825 & CF-A1-1 & CF patient (UK) \\
\hline LMG 17588 & CEP144 & Soil (USA) \\
\hline R-2453 & AU0064 & CF patient (USA) \\
\hline R-2454 & AU0066 & CF patient (USA) \\
\hline $\mathrm{R}-4543$ & $96 / 47$ & CF patient (UK) \\
\hline LMG 18945 & $97 / 35$ & CF patient (UK) \\
\hline $\mathrm{R}-4528$ & HI2249 & CF patient (USA) \\
\hline LMG 14273 & A5P & CF patient (Belgium, 1993) \\
\hline \multicolumn{3}{|l|}{ Burkholderia pseudomallei } \\
\hline R-4038 & CCUG 218 & Sheep (Australia, before 1949) \\
\hline R-4039 & CCUG 13790 & Pus (Thailand, 1983) \\
\hline $\mathrm{R}-4040$ & CCUG 15646 & Ovine spinal abscess (Australia, 1966) \\
\hline
\end{tabular}

\section{RESULTS}

\section{AFLP fingerprinting}

Reproducibility was checked by preparing PCR products in duplicate and was always higher than $92 \%$. Following numerical analysis, 10 clusters could be delineated, while Burkholderia pyrrocinia LMG $14191^{\mathrm{T}}$ occupied a separate position (Fig. 1). The $B$. cepacia genomovar VI strains investigated appeared as a homogeneous group which formed cluster I. Burkholderia gladioli, Burkholderia plantarii and Burkholderia glumae reference strains constituted clusters II, III and VIII, respectively. Reference strains of $B$. vietnamiensis formed cluster IV. Cluster V comprised three $B$. cepacia genomovar III reference strains. Representatives of B. stabilis and B. multi- 


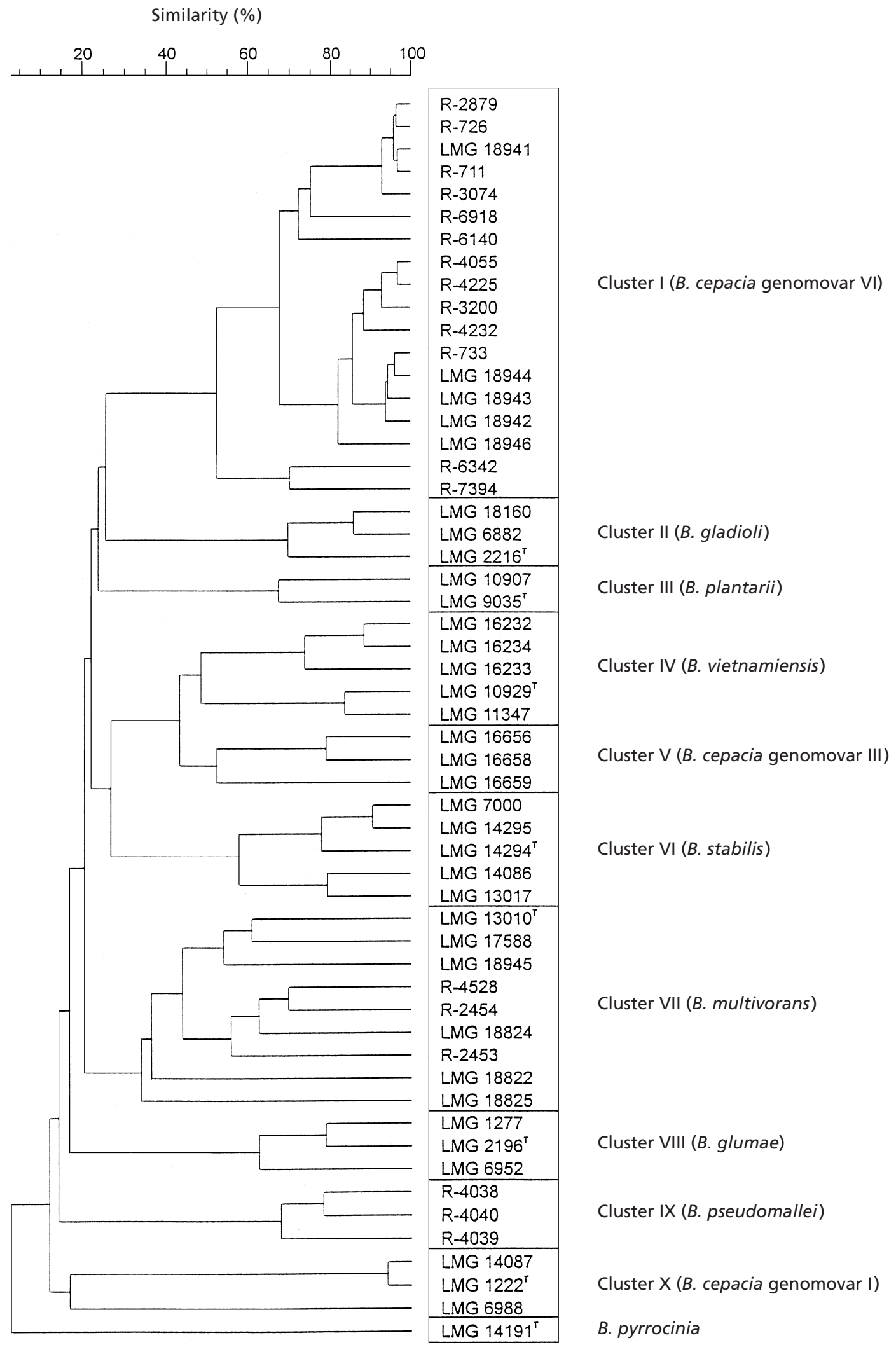

Fig. 1. Dendrogram derived from the unweighted pair group average linkage of correlation coefficients between the AFLP patterns of the strains studied. The correlation coefficient is expressed as percentage similarity for convenience. 


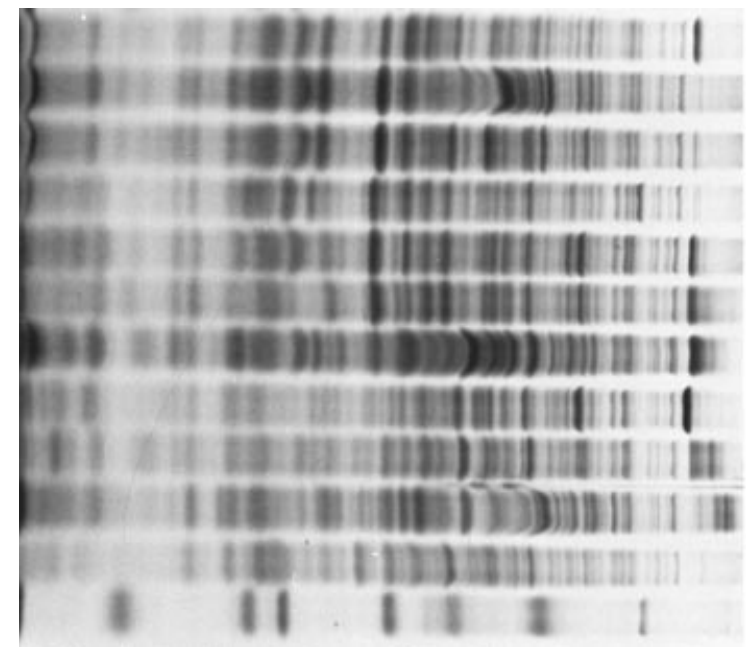

\author{
B. cepacia genomovar VI LMG 18941 \\ B. cepacia genomovar VI LMG 18942 \\ B. cepacia genomovar VI LMG 18943 \\ B. multivorans LMG $13010^{\top}$ \\ B. multivorans R-2453 \\ B. multivorans LMG 18945 \\ B. cepacia genomovar I LMG $1222^{\top}$ \\ B. cepacia genomovar III LMG 16656 \\ B. stabilis LMG $14294^{\top}$ \\ B. vietnamiensis LMG $10929^{\top}$ \\ B. gladioli LMG $2216^{\top}$
}

Fig. 2. Electrophoretic protein patterns of a selection of strains investigated. The molecular mass markers used (lane at the bottom) were (from left to right): lysozyme (14.5 kDa); trypsin inhibitor (20 kDa); trypsinogen (24 kDa); carbonic anhydrase (29 kDa); glyceraldehyde-3-phosphate dehydrogenase (36 kDa); egg albumin (45 kDa); bovine albumin $(60 \mathrm{kDa})$; and $\beta$-galactosidase $(116 \mathrm{kDa})$.

vorans formed clusters VI and VII, respectively. Cluster IX was composed of three Burkholderia pseudomallei strains. Finally, three B. cepacia genomovar I strains, including the type strain, constituted cluster X.

\section{SDS-PAGE of whole-cell proteins}

Reproducibility was checked by preparing protein extracts in duplicate. The correlation level between the patterns obtained with different extracts of the same strain was more than $93 \%$ (data not shown). Following numerical analysis, 'group 13' strains formed two separate clusters. A first cluster contained $12 \mathrm{~B}$. cepacia genomovar VI strains (R-3074, R-733, R-711, LMG 18941, LMG 18942, R-4225, LMG 18944, R6342, LMG 18943, R-6918, R-3200 and R-726). A second cluster contained B. cepacia genomovar VI strains R-4232, R-2879, R-4055, R-7394, LMG 18946 and R-6140, and B. multivorans R-4528, R-4543 and LMG 18945. Two 'group 13' strains (R-2453 and R2454) grouped together with $B$. multivorans reference strains (data not shown). A selection of protein patterns of representative strains of the $B$. cepacia complex and B. gladioli is shown in Fig. 2.

\section{S rRNA gene sequencing}

The 16S rRNA gene sequence of strain LMG 18941 (AF175314) was compared with available 16S rRNA gene sequences of representatives of the $\beta$-Proteobacteria and with the 16S rDNA gene sequences of $B$. multivorans LMG $13010^{\mathrm{T}}$ (AF148555) and B. cepacia genomovar III LMG 16656 (AF148556) (Fig. 3). LMG 18941 was closely related to members of the $B$. cepacia complex, with similarity levels ranging from 98.3 to $99 \cdot 3 \%$. Similarity levels towards other Burkholderia species were between $98 \cdot 1$ and $94 \cdot 8 \%$. Similarity levels towards representatives of other taxa belonging to the $\beta$-Proteobacteria were below $91 \cdot 0 \%$.

\section{DNA-DNA hybridizations and determination of the $\mathbf{G}+\mathbf{C}$ content}

Hybridization results revealed that DNA-DNA binding values between $B$. cepacia genomovar VI LMG 18941 and (i) B. cepacia genomovar I LMG $1222^{\mathrm{T}}$ (53\%), (ii) B. cepacia genomovar III LMG 16656 (37\%), (iii) B. stabilis LMG $7000(44 \%$ ) and (iv) $B$. vietnamiensis $\mathrm{LMG} 10929^{\mathrm{T}}(53 \%)$ were intermediate or low. DNA-DNA binding levels of B. cepacia genomovar VI strains towards representatives of $B$. multivorans were between 47 and $55 \%$ (Table 2). DNA-DNA hybridization experiments carried out between B. cepacia genomovar VI strains LMG 18941, LMG 18942 and LMG 18943 revealed binding levels between 97 and $100 \%$. All B. cepacia genomovar VI strains investigated had $\mathrm{G}+\mathrm{C}$ contents between 66.9 and $67.7 \mathrm{~mol} \%$ (Table 2).

\section{Cellular fatty acid analysis}

The mean fatty acid composition of B. cepacia genomovar VI strains is shown in Table 3. The predominant fatty acids were 16:0, 17:0 cyclo, 19:0 cyclo $\omega 8 c$, summed feature 3 (comprising 14:0 3-OH, 16:1 iso I, an unidentified fatty acid with equivalent chain-length of 10.928, or 12:0 ALDE, or any combination of these fatty acids) and summed feature 7 (comprising $18: 1 \omega 7 c, 18: 1 \omega 9 t$ or $18: 1 \omega 12 t$, or any combination of these fatty acids) (summed features comprise fatty acids that can not be resolved by the Microbial Identification System). Summed feature 3 and summed 


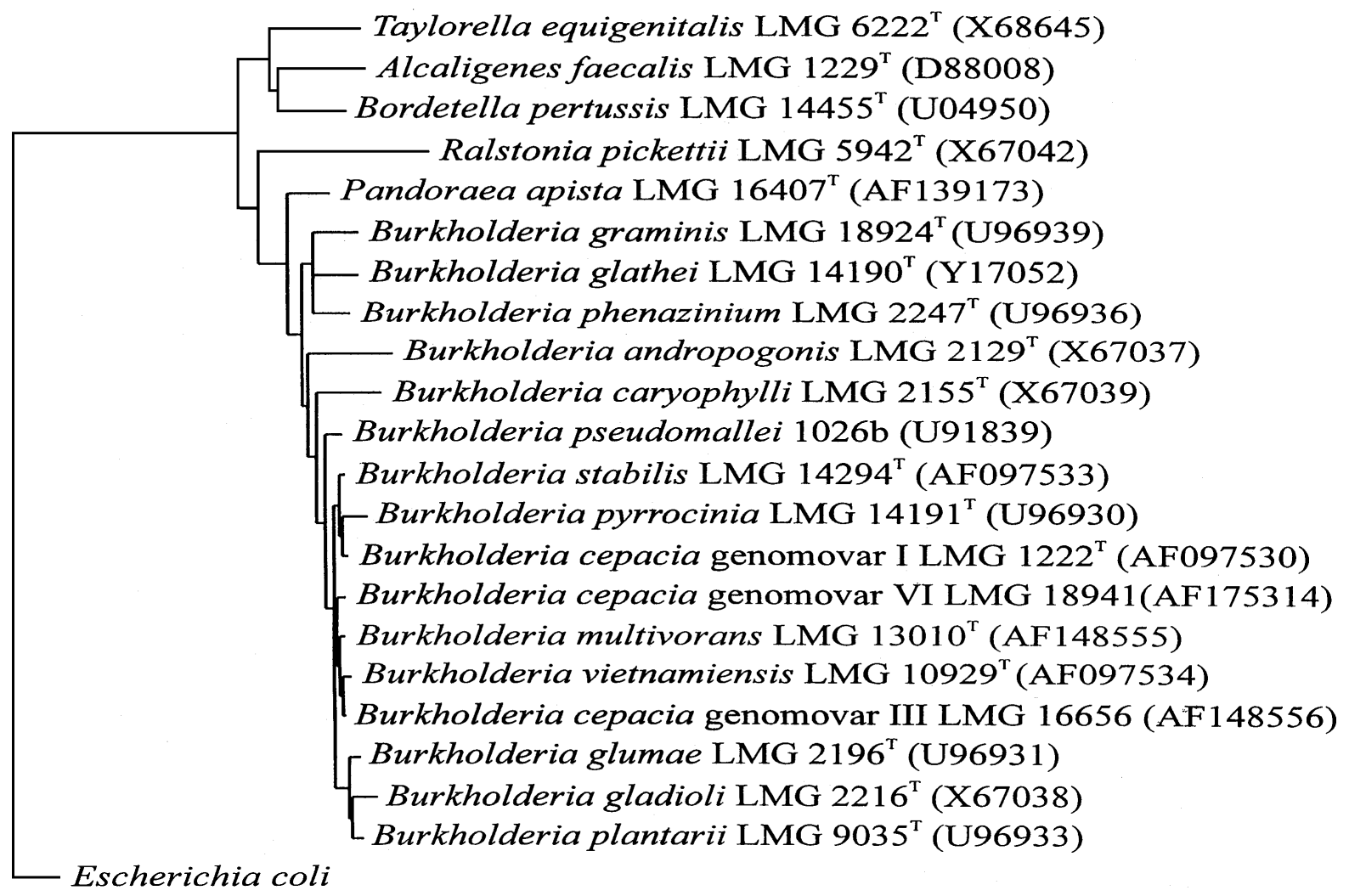

Fig. 3. Neighbour-joining phylogenetic tree showing the position of $B$. cepacia genomovar VI within the $\beta$-Proteobacteria based on 16S rDNA sequence comparisons. Accession numbers are given in parentheses. $E$. coli was used as an outgroup. Bar, $10 \%$ sequence dissimilarity.

Table 2 DNA-DNA binding values and $\mathrm{G}+\mathrm{C}$ content (mol \%) of all strains examined

\begin{tabular}{|c|c|c|c|c|c|c|c|}
\hline \multirow[t]{2}{*}{ Species } & \multirow{2}{*}{$\begin{array}{c}\mathbf{G}+\mathbf{C} \\
(\mathbf{m o l} \%)\end{array}$} & \multicolumn{6}{|c|}{ DNA binding values with strain: } \\
\hline & & LMG 18941 & LMG 18942 & LMG 18943 & LMG $13010^{\mathrm{T}}$ & R-2453 & LMG 18945 \\
\hline \multicolumn{8}{|c|}{ B. cepacia genomovar VI } \\
\hline LMG 18941 & $67 \cdot 4$ & 100 & & & & & \\
\hline LMG 18942 & $66 \cdot 9$ & 100 & 100 & & & & \\
\hline LMG 18943 & $67 \cdot 7$ & 100 & 97 & 100 & & & \\
\hline \multicolumn{8}{|l|}{ B. multivorans } \\
\hline LMG $13010^{\mathrm{T}}$ & $67 \cdot 7$ & 53 & 50 & 48 & 100 & & \\
\hline $\mathrm{R}-2453$ & $67 \cdot 4$ & 55 & & 48 & 87 & 100 & \\
\hline LMG 18945 & $66 \cdot 9$ & & & 47 & 85 & 91 & 100 \\
\hline
\end{tabular}

feature 7 probably correspond to $14: 03-\mathrm{OH}$ and $18: 1 \omega 7 c$, respectively, as these fatty acids have been reported in Burkholderia species (Stead, 1992).

\section{rRNA-based PCR assay}

The 16S rRNA gene of all B. cepacia genomovar VI strains investigated was amplified with primer pair RHG-F and RHG-R, whereas no amplification prod- uct was obtained using primer pair PC-SSF and PCSSR, indicating that the strains belonged to the genera Burkholderia or Ralstonia, but were different from $B$. cepacia genomovars I and III and from $B$. stabilis. Using the B. multivorans-specific primer pair BC-GII and BC-R, an amplicon of 435 bp was obtained for strain R-4232 only. Primer pair BC-V and BC-R (specific for $B$. multivorans and $B$. vietnamiensis) amplified a $848 \mathrm{bp}$ fragment of the 16S rRNA gene of 
Table 3 Fatty acid composition of the strains studied

Composition is expressed as percentage. Those fatty acids for which the mean amount for all taxa was less than $1 \%$ are not given. Mean percentages and standard deviations are given. The number of strains containing the fatty acid is given in parentheses only when not present in all of the strains examined. Tr, trace amount (less than $1 \%$ ).

\begin{tabular}{|c|c|c|c|c|c|c|c|c|c|c|c|c|}
\hline Strain & $14: 0$ & $16: 0$ & $\begin{array}{l}17: 0 \\
\text { cyclo }\end{array}$ & $\begin{array}{c}16: 1 \\
2-O H\end{array}$ & $\begin{array}{c}16: 0 \\
2-\mathrm{OH}\end{array}$ & $\begin{array}{c}16: 0 \\
3-\mathrm{OH}\end{array}$ & 18:0 & $\begin{array}{c}19: 0 \\
\text { cyclo } \omega 8 \mathrm{c}\end{array}$ & $\begin{array}{c}18: 1 \\
2-\mathrm{OH}\end{array}$ & $\begin{array}{c}\text { Summed } \\
\text { feature } 3^{*}\end{array}$ & $\begin{array}{c}\text { Summed } \\
\text { feature } 4^{*}\end{array}$ & $\begin{array}{c}\text { Summed } \\
\text { feature } 7 *\end{array}$ \\
\hline B. cepacia genomovar I (14 strains) $\dagger$ & $3 \cdot 7 \pm 1 \cdot 6$ & $26 \cdot 8 \pm 2 \cdot 8$ & $17 \cdot 9 \pm 3 \cdot 6$ & $\operatorname{Tr}(11)$ & $3 \cdot 3 \pm 0 \cdot 9$ & $6 \cdot 6 \pm 0 \cdot 9$ & $\operatorname{Tr}(13)$ & $12 \cdot 5 \pm 4 \cdot 7$ & $3 \cdot 4 \pm 0 \cdot 8$ & $6 \cdot 0 \pm 1 \cdot 4$ & $4 \cdot 6 \pm 2 \cdot 5$ & $11 \cdot 8 \pm 3 \cdot 5$ \\
\hline B. cepacia genomovar III (48 strains) $\dagger$ & $4 \cdot 2 \pm 0 \cdot 6$ & $26 \cdot 1 \pm 3 \cdot 5$ & $21 \cdot 3 \pm 4 \cdot 2$ & $1 \cdot 3 \pm 0 \cdot 6(38)$ & $3 \cdot 2 \pm 0 \cdot 9$ & $6.7 \pm 1 \cdot 5$ & $2 \cdot 4 \pm 2 \cdot 2(45)$ & $13 \cdot 4 \pm 4 \cdot 9$ & $2 \cdot 3 \pm 1 \cdot 0(41)$ & $6 \cdot 3 \pm 1 \cdot 5$ & $3 \cdot 0 \pm 1 \cdot 0$ & $9 \cdot 3 \pm 4 \cdot 4$ \\
\hline B. stabilis (11 strains) $\dagger$ & $4 \cdot 4 \pm 0 \cdot 5$ & $25 \cdot 6 \pm 4 \cdot 3$ & $17 \cdot 8 \pm 3 \cdot 3$ & $\operatorname{Tr}(8)$ & $4 \cdot 5 \pm 1 \cdot 5$ & $5 \cdot 7 \pm 0 \cdot 9$ & $\operatorname{Tr}(8)$ & $15 \cdot 3 \pm 4 \cdot 2$ & $2 \cdot 4 \pm 0 \cdot 6$ & $5 \cdot 1 \pm 0 \cdot 5$ & $2 \cdot 7 \pm 0 \cdot 8$ & $10 \cdot 7 \pm 1 \cdot 8$ \\
\hline B. vietnamiensis (4 strains) $\dagger$ & $3 \cdot 8 \pm 0 \cdot 6$ & $19 \cdot 5 \pm 2 \cdot 5$ & $14 \cdot 0 \pm 4 \cdot 9$ & $1 \cdot 3 \pm 0 \cdot 2$ & $2 \cdot 8 \pm 0 \cdot 4$ & $6 \cdot 4 \pm 0 \cdot 7$ & $5 \cdot 2 \pm 3 \cdot 4$ & $5 \cdot 8 \pm 2 \cdot 5$ & $3 \cdot 4 \pm 0 \cdot 5$ & $6 \cdot 3 \pm 0 \cdot 9$ & $9 \cdot 8 \pm 2 \cdot 5$ & $19 \cdot 7 \pm 5 \cdot 5$ \\
\hline B. multivorans (14 strains) $\dagger$ & $4 \cdot 8 \pm 0 \cdot 6$ & $28 \cdot 9 \pm 3 \cdot 5$ & $18 \cdot 2 \pm 4 \cdot 9$ & $1 \cdot 3 \pm 0 \cdot 8(12)$ & $2 \cdot 8 \pm 1 \cdot 0$ & $6 \cdot 8 \pm 0 \cdot 5$ & $\operatorname{Tr}(5)$ & $9 \cdot 7 \pm 3 \cdot 3$ & $1 \cdot 3 \pm 0 \cdot 7(12)$ & $6 \cdot 4 \pm 1 \cdot 1$ & $6 \cdot 5 \pm 1 \cdot 5$ & $11 \cdot 5 \pm 4 \cdot 8$ \\
\hline B. gladioli (4 strains) $\dagger^{\dagger}$ & $4 \cdot 9 \pm 0 \cdot 2$ & $29 \cdot 0 \pm 1 \cdot 1$ & $17 \cdot 2 \pm 1 \cdot 9$ & $1 \cdot 5 \pm 0 \cdot 2$ & $3 \cdot 2 \pm 0 \cdot 3$ & $7 \cdot 1 \pm 1 \cdot 0$ & $\operatorname{Tr}$ & $10 \cdot 0 \pm 2 \cdot 7$ & $3 \cdot 5 \pm 0 \cdot 7$ & $6 \cdot 8 \pm 1 \cdot 1$ & $5 \cdot 1 \pm 2 \cdot 3$ & $11 \cdot 0 \pm 3 \cdot 7$ \\
\hline B. cepacia genomovar VI (11 strains) & $4 \cdot 2 \pm 0 \cdot 4$ & $26 \cdot 1 \pm 1 \cdot 4$ & $16 \cdot 0 \pm 2 \cdot 2$ & $1 \cdot 3 \pm 0 \cdot 4$ & $3 \cdot 3 \pm 1 \cdot 0$ & $6 \cdot 2 \pm 0 \cdot 6$ & $\operatorname{Tr}$ & $14 \cdot 8 \pm 3 \cdot 7$ & $1.6 \pm 0.6$ & $8 \cdot 7 \pm 1 \cdot 1$ & $4 \cdot 2 \pm 2 \cdot 0$ & $9 \cdot 9 \pm 4 \cdot 3$ \\
\hline
\end{tabular}

* Summed feature 3 comprises 14:0 3-OH, 16:1 iso I, an unidentified fatty acid with equivalent chain length value of 10.928, or 12:0 ALDE, or any combination of these fatty acids. Summed feature 4 comprises $16: 1 \omega 7 c$ or 15 iso 2 -OH or both. Summed feature 7 comprises 18:1 $\omega 7 c, 18: 1 \omega 9 t, 18: 1 \omega 12 t$, or any combination of these fatty acids.

$\dagger$ Data from Vandamme et al. (1997, 2000).

strains R-6918, R-6140 and R-7394, but not from the other B. cepacia genomovar VI strains.

\section{Phenotypic characterization}

None of the strains tested was able to cause soft rot of onions under the conditions used. Both B. cepacia selective media supported growth of all strains investigated. The following features were present in all strains investigated: oxidase and $\beta$-galactosidase activity, denitrification, growth at $42^{\circ} \mathrm{C}$, acidification of glucose, lactose, maltose, xylose and adonitol and assimilation of glucose, L-arabinose, D-mannose, Dmannitol, $N$-acetylglucosamine, D-gluconate, caprate, adipate, L-malate, citrate and phenylacetate. The following features were absent in all strains investigated: lysine and ornithine decarboxylase, tryptophanase, arginine dihydrolase and urease activity, aesculin hydrolysis, assimilation of maltose, gelatin liquefaction, haemolysis and pigment production.

\section{DISCUSSION}

A polyphasic taxonomic study was performed to characterize 23 strains isolated from CF patients in the United States. Preliminary analysis using the API Rapid NE system identified these strains as members of the B. cepacia complex and this identification was confirmed by key positive biochemical reactions as described previously (Henry et al., 1997). The results of the present study allowed 18 of these strains to be identified as new members of the B. cepacia complex, B. cepacia genomovar VI.

\section{Characterization of $B$. cepacia genomovar VI}

AFLP, a genomic fingerprinting technique based on the selective amplification and visualization of restriction fragments from a total digest of genomic DNA, allowed differentiation of Burkholderia species and genomovars and its results are generally consistent with DNA-DNA hybridization levels (Coenye et al., $1999 \mathrm{~b}$ ). It was also shown that the AFLP procedure is a valuable or even superior alternative for SDS-PAGE of whole-cell proteins to differentiate Burkholderia species (Coenye et al., 1999b). In this study, all $B$. cepacia genomovar VI strains investigated formed a single homogeneous cluster and could easily be differentiated from other Burkholderia species and genomovars (Fig. 1).

It has been reported that SDS-PAGE of whole-cell proteins is a good screening method for the differentiation of members of the B. cepacia complex (Vandamme et al., 1997). However, subsequent studies have shown that, using this method, several $B$. cepacia genomovar I and B. stabilis strains were misidentified (Coenye et al., 1999b; Vandamme et al., 2000). In the present study, it was shown that the majority of 'group 13' strains were identified correctly as B. cepacia genomovar VI, following numerical analysis and visual comparison of the protein profiles; but several $B$. multivorans strains were also identified as B. cepacia genomovar VI.

Comparison of the 16S rDNA sequence of strain LMG 18941 with the available sequences of other Burkholderia species indicated that its closest relatives are members of the B. cepacia complex (similarity levels ranging from 98.3 to $99 \cdot 3 \%$ ). The DNA base ratio of $66.9-67.7 \mathrm{~mol} \%$ is consistent with that of the other members of the B. cepacia complex (67-69 mol \%; Vandamme et al., 1997). However, DNA-DNA hybridizations between LMG 18941 and representative strains of the other members of the $B$. cepacia complex revealed only low or intermediate binding values, whereas DNA-DNA binding values towards strains belonging to the same AFLP cluster (LMG 18942 and LMG 18943) were high. These data unambiguously indicate that this strain represents a novel taxon within the B. cepacia complex. 
Table 4 Phenotypic characteristics useful for the differentiation of $B$. cepacia genomovar VI from other members of the B. cepacia complex and B. gladioli

Strains: 1, B. cepacia genomovar VI (14 strains); 2, B. multivorans (10 strains); 3, B. cepacia genomovar I (11 strains); 4, B. cepacia genomovar III (39 strains); 5, B. stabilis (5 strains); 6, B. vietnamiensis (7 strains); 7, B. gladioli (12 strains). +, All strains give a positive reaction, - , all strains give a negative reaction, v, strain dependent result; all data except for B. cepacia genomovar VI from Vandamme et al. $(1997,2000)$ and own unpublished results.

\begin{tabular}{|c|c|c|c|c|c|c|c|}
\hline Test & 1 & 2 & 3 & 4 & 5 & 6 & 7 \\
\hline Growth at $42{ }^{\circ} \mathrm{C}$ & + & + & - & + & - & - & - \\
\hline$\beta$-Galactosidase activity & + & + & + & + & - & + & + \\
\hline \multicolumn{8}{|l|}{ Decarboxylation of: } \\
\hline Lysine & - & $\mathrm{V}$ & + & + & + & + & + \\
\hline Ornithine & - & - & + & + & + & + & + \\
\hline \multicolumn{8}{|l|}{ Oxidation of: } \\
\hline Sucrose & - & - & + & + & - & + & - \\
\hline Lactose & + & + & + & $\mathrm{V}$ & + & + & - \\
\hline Adonitol & + & + & + & $\mathrm{V}$ & + & + & - \\
\hline Maltose & + & + & + & $\mathrm{V}$ & + & + & - \\
\hline
\end{tabular}

\section{Identification of $B$. cepacia genomovar VI}

Biochemically, B. cepacia genomovar VI cannot be distinguished from $B$. multivorans, but it can be distinguished from the other members of the B. cepacia complex and from $B$. gladioli. The most important differential biochemical tests are summarized in Table 4.

As can be seen in Table 3, the mean fatty acid profile of B. cepacia genomovar VI is virtually indistinguishable from that of the other members of the $B$. cepacia complex and from B. gladioli, although differentiation from $B$. vietnamiensis is possible based on the higher amounts of $16: 0$ and 19:0 cyclow $8 c$ and the lower amounts of 18:0, summed feature 4 and summed feature 7 present in B. cepacia genomovar VI.

Recently, an rRNA-based PCR assay for the identification of B. cepacia complex isolates was described (LiPuma et al., 1999). Most B. cepacia genomovar VI strains did not react with any of the species-specific primers designed against the rRNA operon. One strain (R-4232), however, reacted positively with the primers specific for B. multivorans and three strains (R-6918, $\mathrm{R}-6140$ and R-7394) reacted positively with the primers designed for $B$. vietnamiensis. It was reported that the specificity of these primers was 92 and $99 \%$ for B. vietnamiensis and B. multivorans, respectively (LiPuma et al., 1999). Our results indicate that the specificity of the $B$. vietnamiensis-specific primers will be lower than reported since, as well as some $B$. multivorans strains (LiPuma et al., 1999), B. cepacia genomovar VI strains can give rise to false-positive results. Despite these shortcomings, this PCR assay is a useful and easy tool for the separation of B. cepacia genomovar VI from B. cepacia genomovars I and III and from B. stabilis.

\section{Conclusion}

The results of our genotypic and phenotypic analysis show that these strains belong to a new genomovar within the B. cepacia complex. This new genomovar can be identified by AFLP fingerprinting and DNA-DNA hybridizations and can be separated from $B$. cepacia genomovars I and III, B. stabilis, $B$. vietnamiensis and $B$. gladioli, but not from $B$. multivorans by phenotypic tests and SDS-PAGE of wholecell proteins.

According to the guidelines proposed by Ursing et al. (1995), this new genomic species should be named $B$. multivorans genomovar II, pending the availability of differential diagnostic tests (Wayne et al., 1987; Ursing et al., 1995). However, since B. multivorans was originally known as $B$. cepacia genomovar II, the name $B$. multivorans genomovar II would cause significant confusion. In addition, several strains were initially identified as B. vietnamiensis by species-specific PCR. Given the close relationship of this new organism with the other members of the B. cepacia complex, it is proposed that they are referred to as $B$. cepacia genomovar VI.

Retrospective analysis of epidemiological and genotypic data suggests that strains of B. cepacia genomovar VI can chronically colonize CF patients and may spread from person to person (LiPuma et al., 1990, 1994). Additional studies are needed to ascertain the clinical implications of respiratory tract colonization with this genomovar. B. cepacia genomovar VI strains LMG 18941, LMG 18942, LMG 18943, LMG 18944 and LMG 18946 have been deposited in the BCCM/LMG Bacteria Collection (University of Gent, Gent, Belgium).

\section{ACKNOWLEDGEMENTS}

T.C. acknowledges the support received from the Vlaams Instituut voor Bevordering van Wetenschappelijk-technologisch onderzoek in de Industrie (Belgium) in the form of a bursary for advanced study. P.V. and M.G. are indebted to the Fund for Scientific Research-Flanders (Belgium) for a position as a postdoctoral fellow and for research and personnel grants, respectively. J. L. and D.P. S. acknowledge the financial support received from the Cystic Fibrosis Foundation (USA) and the Canadian Cystic Fibrosis Foundation (Canada), respectively. We acknowledge the financial support received from the Cystic Fibrosis Trust (UK) (grant RS15) and wish to thank Dr J.R.W. Govan for critical reading of the manuscript, Johan Goris for the determination of the $\mathrm{G}+\mathrm{C}$ content and Dirk Dewettinck, Severine Laevens and Urbain Torck for excellent technical assistance.

\section{REFERENCES}

Coenye, T., Falsen, E., Vancanneyt, M., Hoste, B., Govan, J. R. W., Kersters, K. \& Vandamme, P. (1999a). Classification of some Alcaligenes faecalis-like isolates from the environment and 
human clinical samples as Ralstonia gilardii sp. nov. Int $J$ Syst Bacteriol 49, 405-413.

Coenye, T., Schouls, L. M., Govan, J. R. W., Kersters, K. \& Vandamme, P. (1999b). Identification of Burkholderia species and genomovars from cystic fibrosis patients by AFLP fingerprinting. Int J Syst Bacteriol 49, 1657-1666.

Ezaki, T., Hashimoto, Y. \& Yabuuchi, E. (1989). Fluorometric deoxyribonucleic acid-deoxyribonucleic acid hybridization in microdilution wells as an alternative to membrane filter hybridization in which radioisotopes are used to determine genetic relatedness among bacterial strains. Int $J$ Syst Bacteriol 39, 224-229.

Gillis, M., Van Van, T., Bardin, R. \& 7 other authors (1995). Polyphasic taxonomy in the genus Burkholderia leading to an emended description of the genus and proposition of Burkholderia vietnamiensis sp. nov. for $\mathrm{N}_{2}$-fixing isolates from rice in Vietnam. Int J Syst Bacteriol 45, 274-289.

Gonzalez, C. F. \& Vidaver, A. K. (1979). Bacteriocin, plasmid and pectolytic diversity in Pseudomonas cepacia of clinical and plant origin. J Gen Microbiol 110, 161-170.

Henry, D. A., Campbell, M. E., LiPuma, J. J. \& Speert, D. P. (1997). Identification of Burkholderia cepacia isolates from patients with cystic fibrosis and use of a simple new selective medium. $J$ Clin Microbiol 35, 614-619.

Hugh, R. \& Leifson, E. (1953). The taxonomic significance of fermentative versus oxidative metabolism of carbohydrates by various Gram-negative bacteria. J Bacteriol 66, 24-26.

LiPuma, J. J. (1998a). Burkholderia cepacia: management issues and new insights. Clin Chest Med 19, 473-486.

LiPuma, J. J. (1998b). Burkholderia cepacia epidemiology and pathogenesis: implications for infection control. Curr Opin Pulm Med 4, 337-441.

LiPuma, J. J., Dasen, S. E., Nielson, D. W., Stern, R. C. \& Stull, T. L. (1990). Person-to-person transmission of Pseudomonas cepacia between patients with cystic fibrosis. Lancet 336, 1094-1096.

LiPuma, J. J., Marks-Austin, K. A., Holsclaw, D. S., Winnie, G. B., Gilligan, P. H. \& Stull, T. S. (1994). Inapparent transmission of Pseudomonas (Burkholderia) cepacia among patients with cystic fibrosis. Pediatr Infect Dis J 13, 716-719.

LiPuma, J. J., Dulaney, B. J., McMenamin, J. D., Whitby, P. W., Stull, T. L., Coenye, T. \& Vandamme, P. (1999). Development of rRNA-based PCR assays for identification of Burkholderia cepacia complex isolates recovered from cystic fibrosis patients. $J$ Clin Microbiol 37, 3167-3170.

Mesbah, M., Premachandran, U. \& Whitman, W. B. (1989). Precise measurement of the $\mathrm{G}+\mathrm{C}$ content of deoxyribonucleic acid by high-performance liquid chromatography. Int $J$ Syst Bacteriol 39, 159-167.

Pitcher, D. G., Saunders, N. A. \& Owen, R. J. (1989). Rapid extraction of bacterial genomic DNA with guanidium thiocyanate. Lett Appl Microbiol 8, 109-114.

Pot, B., Vandamme, P. \& Kersters, K. (1994). Analysis of electrophoretic whole-organism protein fingerprints. In Chemical Methods in Prokaryotic Systematics, pp. 493-521. Edited by M. Goodfellow \& A. G. O'Donnell. Chichester: Wiley.

Saitou, N. \& Nei, M. (1987). The neighbor-joining method: a new method for reconstructing phylogenetic trees. Mol Biol Evol 4, 406-425.

Stead, D. E. (1992). Grouping of plant-pathogenic bacteria and some other Pseudomonas spp. by using cellular fatty acid profiles. Int J Syst Bacteriol 42, 281-295.

Ursing, J. B., Rossello-Mora, R. A., Garcia-Valdes, E. \& Lalucat, J. (1995). Taxonomic note: a pragmatic approach to the nomenclature of phenotypically similar genomic groups. Int J Syst Bacteriol 45, 604.

Vandamme, P., Vancanneyt, M., Pot, B. \& 10 other authors (1992). Polyphasic taxonomic study of the emended genus Arcobacter with Arcobacter butzleri comb. nov. and Arcobacter skirrowii sp. nov., an aerotolerant bacterium isolated from veterinary specimens. Int J Syst Bacteriol 42, 344-356.

Vandamme, P., Holmes, B., Vancanneyt, M. \& 8 other authors (1997). Occurrence of multiple genomovars of Burkholderia cepacia in cystic fibrosis patients and proposal of Burkholderia multivorans sp. nov. Int J Syst Bacteriol 47, 1188-1200.

Vandamme, P., Mahenthiralingam, E., Holmes, B., Coenye, T., Hoste, B., De Vos, P., Henry, D. \& Speert, D. P. (2000). Identification and population structure of Burkholderia stabilis sp. nov. (formerly Burkholderia cepacia genomovar IV). J Clin Microbiol 38, 1042-1047.

Wayne, L. G., Brenner, D. J., Colwell, R. R. \& 9 other authors (1987). International Committee on Systematic Bacteriology. Report of the ad hoc committee on reconciliation of approaches to bacterial systematics. Int J Syst Bacteriol 37, 463-464. 